\title{
POLARIZAÇÃO PARTIDÁRIA E RUPTURA COM O SISTEMA DEMOCRÁTICO: AS RELAÇÕES ENTRE EXECUTIVO E LEGISLATIVO NO CHILE ENTRE 1970 E 1973
}

\author{
Janaina Capistrano \\ Mestre em Sociologia pela UNESP \\ e Doutoranda em História Social pela FHDSS - Campus de Franca, UNESP \\ E-mail: janacapis@yahoo.es
}

\begin{abstract}
RESUMO
Em setembro de 1973, um violento golpe militar marcou o fim do governo de Salvador Allende iniciado em 1970 e o colapso do sistema democrático chileno. Em termos políticos, este período pode ser reconhecido pela ascendente polarização ideológica entre os partidos e por uma intensa dinâmica de deslegitimação das instituições políticas. O objetivo deste artigo é realizar um mapeamento de algumas das análises que de certa forma se debruçaram sobre a "experiência chilena" observando esses dois aspectos, e um apontamento coeso das possibilidades para uma análise deste processo político através da perspectiva institucional.

Palavras-Chave: Polarização partidária. Executivo e Legislativo. "Experiência chilena”.
\end{abstract}

\section{AbSTRact}

On September, 1973, a violent militar "coup d'état" marked the end of Salvador Allende's government, started in 1970, and Chile's democratical system colapse. In political therms, that period may be recognized through the ascendant ideological polarization among the parties and through an intense dynamics of loss of legitimization of the political institutions. This article aims to realize a mapping out of some of the investigations that, in a way, studied the "Chilean experience", focusing those two aspects, and a coherent appointment of the possibilities for an investigation of the political process through the institutional perspective.

Key Words: Party polarization. Executive and Legislature. "Chilean Experience".

\section{Introdução}

Após a onda de rupturas com o sistema democrático na América Latina durante as décadas de 1960 e 1970, abriu-se um intenso debate sobre suas causas e as formas de evitá-las no futuro. Desse debate e sob diferentes enfoques originou-se um grande numero de proposições teórico-analíticas que, em ultima instancia, possuem uma postura à favor da consolidação da democracia. Dentre elas, destacamos a que possui uma perspectiva institucional e concentra-se em torno à questão de qual regime político, com quais mecanis- 
mos institucionais, poderia favorecer ou evitar crises sistêmicas profundas. No bojo dessa perspectiva estão às avaliações das conjunturas nas quais, e pelas quais, se produziram ditas crises.

Nas analises políticas desenvolvidas sobre as diferentes experiências dos distintos países da região latino-americana desde a perspectiva apontada, o Chile ocupa um lugar de destaque devido à sua proclamada estabilidade democrática e às singularidades dos seus processos políticos.

Desses processos, se sobressai a tentativa de conduzir à prática a "via chilena ao socialismo", um programa de governo que propunha realizar a transição para o socialismo por meio das instituições do Estado democrático representativo.

Decorridos três anos dessa experiência, um golpe militar pôs fim ao regime presidencial democrático em setembro de 1973 e instalou no país um regime ditatorial, que durou dezessete anos.

Até aquele momento de ruptura, os chilenos tinham estabelecido uma dinâmica político-institucional que lhes garantiu um período apreciável marcado por sucessivos governos constitucionais, justamente num contexto regional caracterizado pelos governos autoritários.

Diante desta realidade, emergiram duas questões principais: se o Chile possuiu uma democracia estável, o que a possibilitou? e; porque essa democracia ruiu?

O objetivo central desse artigo é delinear, por meio de uma resenha bibliográfica, as principais reflexões que giraram em torno a estas duas questões.

Logo, o presente texto está dividido em três momentos. No primeiro, se realiza um diálogo entre alguns autores que discorrem sobre a idéia de excepcionalidade chilena, bem como sobre a incidência dessa concepção sobre as opções políticas no país. Em seguida, dá-se voz às interpretações que, apropriando-se da perspectiva institucional, se debruçaram sobre o colapso da democracia no Chile.

Por fim, se formula um breve referencial sobre a possibilidade de investigação sobre a experiência chilena a partir da perspectiva institucional.

\section{Do mito à realidade: desvendando a idiossincrasia política chilena.}

Para Aggio (1997) e também para Cáceres e Garrido (1997) um conjunto de idéias, formuladas a partir de hipóteses explicativas que buscaram no processo de consolidação do Estado nacional chileno as raízes da estabilidade democrática e da sua ruptura, ajudou a criar uma imagem de que o país avançava em direção à modernidade em disparidade com a América Latina e com o processo de modernização na região ${ }^{1}$.

Um importante trabalho analítico que caminharia na direção apontada 
por estes autores seria o de Pinto (1970). Para Pinto, durante o processo de consolidação do Estado nacional o Chile não passou pela etapa caudilhista comum a outros países.

Isso teria ocorrido, porque a oligarquia local racionalizou seu predomínio de classe numa representação civil, estabelecendo uma confluência entre poder econômico e poder político e, assim, hegemonizando o poder estatal.

Segundo este autor, naquele momento a economia do país ainda era destituída de fortes vínculos com o comercio internacional e, portanto não integrada ao capitalismo liberal. Neste sentido o grupo social que ascendeu ao poder político era formado por uma aristocracia fundiária regional.

De acordo com esta interpretação, o singular do processo político chileno residiria no fato de que, enquanto outros países latino-americanos consolidaram seus Estados nacionais concomitantemente à plena integração de suas economias ao capitalismo liberal, o Chile o haveria realizado anteriormente.

Estas idéias dão forma à conhecida tese de que o país demonstrou um expressivo adiantamento do desenvolvimento da estrutura político-institucional em relação à estrutura produtiva, o que teria lhe garantido vivenciar sucessivas experiências democráticas durante quase todo o século XX.

Aggio (1997), afirma que esta imagem de moderno foi se cristalizando ao longo dos anos na medida em que ganhou correspondência com determinados acontecimentos políticos. Como por exemplo, a implantação do parlamentarismo como regime de governo na virada do séc. XIX para o XX, a responsabilidade assumida pelo Estado em relação ao predomínio estrangeiro nos negócios do salitre e do cobre, e a consolidação de uma estrutura partidária capaz de representar os mais distintos grupos sociais.

Dessa forma, uma mescla entre mito e realidade teria contribuído para criar a sensação na classe política, de que o país estaria apto a viver distintas -e às vezes radicais- experiências políticas dada a sua modernidade intrínseca.

Contudo, as formas desse mito foram sendo desvendadas pelos distintos investigadores da sociedade chilena ao longo das ultimas décadas do séc. XX e principalmente depois do violento golpe militar de 1973.

Foi identificado por Cáceres e Garrido (1997) que a despeito de ter se estabelecido nas instituições políticas um sistema de representação civil (e não militar), a confluência entre poder econômico e político não determinou o predomínio unicamente da classe fundiária.

\footnotetext{
${ }^{1} \mathrm{O}$ conceito de "modernidade" aqui utilizado se refere ao desenvolvimento da racionalidade normativa (democracia representativa, soberania popular, direitos políticos, direitos sociais, e etc.) no sentido da reafirmação da autonomia moral e política de uma nação. Já o conceito de "modernização" se refere ao desenvolvimento da racionalidade instrumental, que diz respeito ao processo produtivo de uma sociedade. Ambas definições estão baseadas nos conceitos apresentados por Lechner (1990).
} 
Para ambos os autores a expansão do comércio exterior já desde 1820 requereu do Estado uma "adaptação mercantilista". Isso explicaria por que as instituições políticas além de concentrar interesses estritamente fundiários, também privilegiavam os interesses mercantis (CÁCERES; GARRIDO, 1997, p. 33) ${ }^{2}$, revelando-nos que a disparidade estrutural de desenvolvimento apontada por Pinto (1970) não foi, ao menos, tão profunda.

A isso se pode agregar, que a ordem política democrática demorou algum tempo para estabilizar-se. Pelo menos até 1860, o país esteve grande parte do tempo submetido a regimes de emergência o que fez com que a ordem constitucional operasse apenas nominalmente, tal como demonstrou Jocelyn-Holt. Além disso, afirma o autor, que a capacidade do Estado chileno em assumir sua centralidade esteve debilitada até um pouco antes do final do século, em virtude de que ainda não tinha obtido nenhuma fonte de renda segura que o provesse de recursos para executar seus projetos (JOCELYNHOLT, 1997) ${ }^{3}$. Isto somente foi possível a partir de 1881 através da integração econômica do país baseada nas exportações de salitre ${ }^{4}$. Estas exportações garantiram um expressivo aumento do ingresso nacional, por conseguinte da tributação e dos gastos fiscais.

Se ainda for adicionado a dimensão participativa, fica evidente que entre a Constituição de 1833 e a subseqüente, a de 1925, o caráter do sufrágio foi bastante restringido. Limitações de idade (direito concedido somente a maiores de 25 anos), gênero (somente os homens) e renda, que foi modificada em 1874 para a capacidade de ler e escrever, restringiram este direito a um limitado grupo da sociedade (DUJISIN, 1989).

Por fim, estes dados possibilitam uma reflexão a respeito da fragilidade das instituições políticas democráticas durante a consolidação do Estado nacional no Chile. Também possibilita, por outro lado, indagar sobre a fragilidade da tese de que esta consolidação deu-se anteriormente à integração econômica. Tal procedimento reforça a idéia da existência do

\footnotetext{
${ }^{2} \mathrm{~A}$ referida adaptação haveria garantido privilégios aos interesses mercantis como por exemplo, a livre gestão interna dos comerciantes e um conjunto de isenções tributárias. Os autores afirmam que tem sido quase um dogma sustentar que a classe dominante no Chile foi, desde 1830 até 1920, a aristocracia fundiária e que o regime político compreendido entre a Constituição de 1833 e a de 1925 constitui-se na forma clássica de Estado latifundiário. Contudo, uma analise mais aprofundada do tema revelou que os comerciantes foram quem hegemonizaram o processo e modelaram o Estado sob a influência das casas comerciais.

${ }^{3}$ Para esse autor, a capacidade do Estado chileno, neste período, em garantir a convivência pacifica e moldar a sociedade mediante políticas públicas é bastante limitada. $\mathrm{O}$ aparato político não possuía sustentação administrativa para tanto, mesmo que entre 1845-1870 o aparato administrativo se duplicou, seguiu com modestas dimensões. Somente em 1919 o numero de funcionários públicos se tornou nove vezes maior que em 1880 .

${ }^{4}$ As salitreiras no norte do país foram apropriadas em 1880 através da Guerra do Pacifico, investida pelo Chile contra Peru e Bolívia.
} 
mito da "democracia perfeita".

Sobre o caráter do sistema político neste período, vários autores acordam que durante o século XIX, todos os que ascenderam ao poder político estatal provinham de um mesmo grupo social de elite, é portanto razoável classificá-lo como oligárquico ${ }^{5}$.

O Chile adentrou o século XX em meio à crise desse mesmo sistema político, que para ser superada necessitou do protagonismo do Estado na promulgação de uma nova Constituição em 1925.

Segundo Verdugo (1998), as principais transformações constitucionais foram: diferenciar nacionalidade e cidadania através do artigo intitulado garantias constitucionais, qualificar o Estado chileno como unitário, republicano e democrático, restabelecer o presidencialismo como regime de governo e fixar os campos de atuação do Executivo e do Legislativo, estabelecer seis anos de mandato para o Presidente, impossibilitar a reeleição para o período posterior imediato, delegar ao Congresso Nacional a responsabilidade pela eleição entre primeira e segunda maioria relativa quando não houvesse um vencedor majoritário, separar eleições parlamentar e presidencial, estabelecer legalmente a separação entre igreja e Estado, criar registros eleitorais e regular o sistema de partidos. $\mathrm{O}$ direito a voto continuou restringido para os menores de 21 anos, mulheres e analfabetos ${ }^{6}$.

A Carta de 25 demarcou o inicio de uma nova etapa para o Estado chileno, tanto no que diz respeito às funções das instituições representativas, como para o modelo de relações entre os poderes do Estado, especialmente entre o Executivo e o Legislativo. Além disso, a Constituição reorganizou, do ponto de vista institucional, as relações entre política e sociedade. (MOULIAN, 1993) ${ }^{7}$

Contudo, segundo Moulian (1993) se estabeleceu no país uma competição política regulada, uma estrutura de partidos dotados de programa, base estável e fortes lideranças, somente no segundo qüinqüênio da década de 30. Aggio (1993) afirma que, as eleições parlamentares de 1937 e as presidenciais de 1938 (pela qual venceu uma coalizão de centro-esquerda chamada "Frente Popular”) demonstraram uma reconfiguração do espectro político chileno.

\footnotetext{
${ }^{5}$ Dentre estes autores destacamos: Aggio, (1993, 1997), Cáceres e Garrido (1997), Jocelin-Holt (1997) e Garreton e Moulian (1983).

${ }^{6}$ As mulheres puderam exercer direito a voto somente a partir das eleições municipais de 1934 e nas demais eleições a partir de 1949 .

${ }^{7}$ Aggio (1993), demarca duas etapas, de 1920 a 1925 e de 1932 a 1938, do processo de esgotamento da forma política oligárquica, a primeira marcada pelo reformismo e a segunda pela postura defensiva da ala conservadora, não obstante, utilizo a Constituição de 25 como marco institucional do inicio de um outro processo político no qual o Estado passa a assumir feições de "Estado de compromisso".
} 
Este mesmo autor observa ainda, sobre tal contexto, que as forças de esquerda, que até 1932 representaram pautas anti-sistema, vislumbrando a possibilidade de inclusão política adotaram uma estratégia mais orientada à participação e defesa da democracia. Sua forte presença político eleitoral, por meio do Partido Comunista e do Partido Socialista, iniciou uma conjuntura partidária caracterizada pelo movimento pendular dos partidos de esquerda e direita em direção ao centro. ${ }^{8}$

Esta dinâmica institucionalizou-se tanto no Legislativo como no Executivo através das coalizões eleitorais. Tais coalizões vincularam o debate na arena política contribuindo, assim, para a formulação e aplicação de distintas políticas públicas. Dessa maneira, como em outros países da América Latina, o Estado chileno teria assumido partir deste momento as rédeas do desenvolvimento do capitalismo industrial (AGGIO, 1993).

No entanto, o singular do processo chileno residiria no fato de que o sistema de coligações e negociações partidárias permitiu que os programas de desenvolvimento para o país representassem os interesses dos diversos setores da sociedade promovendo, desta forma, além da modernização do processo produtivo, a democratização e a justiça social. Nesse percurso, de 1938 até 1973, dinamizou-se no país um processo crescente de democratização, mas que, no entanto, não teria sido linear e nem global (MOULIAN, 1982, 1985; AGGIO, 1993, 1997).

Elaborando uma periodização desse processo, Moulian (1982) o divide em três momentos; num primeiro momento (1938-1947) evidencia-se o equilíbrio entre desenvolvimento econômico e desenvolvimento político; num segundo (1947-1958) há um retrocesso da democratização e o autor o caracteriza como período de "democracia protegida" , o terceiro momento (19581973) é caracterizado como "democracia de massas" e foi vivido pela sociedade chilena como um momento de inclusão e profunda politização. Nele está inserido o último período de governo democrático (1970-1973) anterior aos seguintes dezessete anos de autoritarismo no Chile.

\section{O conflito partidário no governo da Unidade Popular e a ruptura} com a democracia chilena.

Em 1970, os principais partidos políticos chilenos, encontravam-se distribuídos tripartitamente no espectro político. Centro, direita e esquerda apresentaram seus candidatos para presidente encabeçando três programas

\footnotetext{
${ }^{8} \mathrm{O}$ caráter moderado do centro estimulou uma política defensiva da direita ao mesmo tempo que obrigou a esquerda a uma estratégia de compromisso segundo Aggio (1993).

${ }^{9}$ Neste período é promulgada a "Ley de defensa de la democracia" que torna ilegal o Partido Comunista chileno e suprime os direitos cidadãos de quem nele milita, sublinha Dujisin (1989).
} 
de governos distintos, mas tendo uma orientação política comum: a inquestionável legitimidade do sistema político e das instituições políticas.

O contexto desta eleição esteve marcado pela intensa participação social na vida política, pela formação de um espectro político polarizado que rompeu com a política pendular de partidos, e por uma grave crise do papel de regente da economia e da democratização assumido pelo Estado. (AGGIO, 1998).

Apresentando-se o quadro político das eleições de 1970, tornou-se evidente a divisão dos partidos, e da base social que os apoiava. No dia quatro de setembro desse ano, Salvador Allende Gossens ${ }^{10}$ candidato representante da Unidade Popular ${ }^{11}$ venceu a disputa pela presidência da república com $36,2 \%$ dos votos, contra 34,9\% de Jorge Alessandri representante da direita e 27,8\% de Radomiro Tomic candidato do centro democrata cristão (AGGIO, 1993).

O programa de governo apresentado pela Unidade Popular propunha realizar a transição para o socialismo por meio das instituições do Estado democrático representativo. Esta proposta ficou conhecida como "via chilena ao socialismo" e a tentativa de conduzi-la à prática, durante três anos de governo, constitui-se no processo político conhecido como "experiência chilena" (AGGIO, 1998).

Para Sartori (1993) e Valenzuela $(1989,1998)$, como as instituições políticas chilenas combinavam multipartidismo e presidencialismo, o Executivo teve que lidar com uma dupla dificuldade para viabilizar seu projeto: não contar com maioria no Congresso ${ }^{12}$ e ter de negociar através de um "sistema de partidos polarizado". ${ }^{13}$

\footnotetext{
${ }^{10}$ Allende era médico, ajudou a fundar o Partido Socialista em 1933, elegeu-se seu secretário regional no mesmo ano, em 1936 participou da coalizão política denominada Frente Popular, em 1937 elegeu-se deputado por Valparaiso e subsecretário geral do PS, em 1939 foi nomeado ministro da saúde do governo Aguirre Cerda, em 1940 elegeu-se secretário geral do PS, em 1945 elegeu-se senador, em 1952 candidatou-se à presidência por uma coalizão de nome "Frente do Povo", em 1953 elegeu-se senador, em 1954 foi vice-presidente do senado, em 1958 candidatou-se à presidência e acabou ficando em segundo lugar com uma diferença de 30.000 votos do primeiro lugar Jorge Alessandri, em 1961 elegeu-se senador, 1964 candidatou-se à presidência pela coligação FRAP (frente de ação popular), em 1967 foi presidente do senado, em 1969 elegeu-se senador e em 1970 elegeu-se presidente da república.

${ }^{11}$ Coligação de partidos de esquerda e centro-esquerda formada pelos seguintes partidos: Partido Comunista, Partido Socialista, Partido Social Democrata, Partido Radical, Ação Popular Independente, e Movimento de Ação Popular Unificado.

12 Os parlamentares deste período foram eleitos em 1969, a casa só se renovaria através das eleições de março de 1973.

${ }_{13}$ Segundo Sartori (1982, p.156-170), o "sistema de partidos polarizado" se configura ao somar-se características tais como: a presença de partidos "anti-sistema" -que enfraquecem a legitimidade do regime-, de "oposições bilaterais" -incapacitadas de unirem-se em uma única oposição-, e de um "centro métrico" -que dificulta a interação bipolar e os impulsos centrípetos entre os partidos. Valenzuela é adepto de sua teoria sobre sistemas de partidos.
} 
Tais dificuldades se expressaram claramente no interlúdio compreendido entre a vitória de Allende e sua posse formal em 11 de novembro de 1970. Nesse ínterim, as três grandes forças do espectro político se mobilizaram para garantir o resultado da votação no Congresso entre primeira ou segunda maioria. A direita buscou negociar com o centro a fim de garantir a votação a favor de Alessandri ${ }^{14}$, a Democracia Cristã negando tal acordo propôs uma coalizão com a esquerda oferecendo seu apoio a Allende e exigindo uma reforma no art. 10 da Constituição.

Por essa reforma, intitulada "estatuto de garantias constitucionais" deveriam votar juntos no legislativo, os representantes do centro e da esquerda. Imediatamente após aprovada no Congresso Nacional os democrata cristãos votaram pela primeira maioria relativa. ${ }^{15}$

As relações entre esquerda, centro e direita foram tornando-se mais tensas à medida que o programa de governo foi posto em prática. (AGGIO 1993) A principal estratégia adotada pela UP, para garantir rapidez ao processo de reformas e por conseguinte de transformações estruturais, foi a de utilizar o caminho extra-parlamentar, percorrido por meio da aplicação de decretos-lei. As reformas mais significativas, como por exemplo as da área econômica, foram realizadas através desse mecanismo ${ }^{16}$.

Para Aggio (1993) os conflitos gerados pelos grupos sociais que reagiram contra as reformas, uma vez cooptados pelo Partido Nacional (direita) e pela Democracia Cristã (centro), foram institucionalizados e traduziram-se em um confronto aberto entre o Legislativo e o Executivo. Ao final de dois anos de governo, afirma o autor, instalou-se um "jogo de anteposição de blocos", pois, depois da grave crise econômica, social e política de outubro de $1972^{17}$, centro e direita convergiram para uma mesma oposição.

\footnotetext{
${ }^{14}$ Nessa negociação os lideres de direita propuseram aos lideres da democracia cristã a votação conjunta por Alessandri, este por sua vez depois de eleito renunciaria em nome de uma nova eleição e de uma nova candidatura de um democrata cristão o qual apoiaria formando uma ampla coalizão.

${ }^{15}$ É interessante notar que o mecanismo institucional ao qual nos referimos aqui, ou seja, o de votação do Congresso pela primeira ou segunda maioria, estimulou a negociação entre o centro e a esquerda, contudo não pôde ser responsável pela formação de um governo de coalizão. Isso, porque, os próprios partidos envolvidos nas negociações insistiram que mesmo após a votação por Allende eles permaneceriam independentes entre sí, o que sinalizava o grau de radicalização entre eles.

${ }^{16} \mathrm{~A}$ atribuição de faculdades legislativas ao Executivo foi outorgada pela reforma constitucional de 1970.

${ }^{17}$ Em outubro de 1972 houve uma paralisação quase total das atividades no Chile, a greve dos médicos e dos caminhoneiros paralisou serviços básicos para a população. O confronto entre governo e oposição exacerbou-se a ponto dos presidentes da Câmara de Deputados e do Senado recusarem-se a dialogar com Allende, que decretou estado de emergência no país. A esquerda empreendeu uma ampla mobilização de massas que legitimou as ações do governo, este por sua vez ao início de novembro para acalmar a ofensiva política da oposição formou um novo gabinete ministerial com a presença de militares.
} 
Este cenário demonstrou que a polarização havia chegado ao seu ápice, em tal contexto as eleições parlamentares de março de 1973 representaram para as forças políticas a variável que definiria o futuro do governo. Nesta eleição, centro e direita agrupados em um único bloco político, chamado "confederação democrática", obtiveram 55\% dos votos contra 44\% da esquerda. ${ }^{18}$

Tal resultado impossibilitou que a oposição formasse um quorum qualificado de dois terços mais um no Congresso, isso garantiu ao governo a possibilidade de veto parcial sobre os projetos apresentados pelo legislativo ${ }^{19}, \mathrm{e}$ a impediu de votar a destituição do Presidente e uma reforma constitucional, ambas medidas necessitavam da mesma proporção de votos em cada Câmara. Mas esses mecanismos eram insuficientes para levar adiante um programa de governo e constituíam apenas recursos neutralizadores (CÁCERES; GARRIDO, 1997).

Por outro lado, a oposição no legislativo possuía maioria simples, o que lhe garantia rechaçar, em primeira instancia os projetos com iniciativa no Executivo que considerasse inconstitucionais. De maio a junho de 73 foram rechaçados os seguintes projetos oriundos do Executivo: lei para delitos econômicos, lei para criar o ministério da família, lei para regular participação dos trabalhadores nas fábricas, lei para criar ministério do mar e lei para formação de empresas de autogestão, a lei de reajuste e salário para trabalhadores é primeiro adiada e depois aprovada sem financiamento, até julho mais vinte projetos de lei orçamentaria foram aprovados sem financiamento.

Finalmente, a anteposição entre governo e oposição produziu uma paralisação total das instituições políticas desencadeando sua deslegitimação ${ }^{20}$. Em pouco tempo a democracia chilena entrou em uma crise sem precedentes, a qual despertou a intervenção militar em 11 de setembro de 1973.

Inúmeras interpretações e explicações, para o fracasso da "via chilena" e para o fato de uma democracia que parecia estar consolidada ruir, foram elaboradas após 73 .

\footnotetext{
${ }^{18}$ De acordo com Sartori (1982, p.72), “[...] Em 1973, a Frente de Unidade Popular - PS, MAPU, PCCh, API (Partido Socialista, Movimento de Ação Popular Unificado, Partido Comunista chileno, Ação Popular Independente.) - obteve $42,1 \%$ dos votos (um aumento de seis cadeiras na Câmara e duas no Senado), e a oposição (CODE), 56,2\%. [...]".

${ }^{19}$ A Constituição de 1925 estabelece que todo projeto de lei que tenha sido aprovado pelas duas Câmaras deve ser apresentado ao Presidente para sua promulgação. Se este o desaprova, o projeto é devolvido à sua Câmara de origem para as modificações indicadas. Se o Congresso aprova as modificações o projeto passa a ter força de lei, caso contrário, sua aprovação dependerá da votação a favor de dois terços mais um, em cada Câmara.

${ }^{20}$ Para Sartori (1982, p.236), "[...] Vale notar que, a 22 de agosto de 1973, o Congresso aprovou uma moção de 'ilegalidade' do governo de Allende, que resultou na renúncia dos militares que faziam parte do gabinete e contribuiu, sem dúvida, para legitimar o golpe militar de 11 de setembro. [...]".
} 
Para Garreton e Moulian (1983), o rompimento com a democracia chilena representou o desfecho de uma crise no modelo de desenvolvimento nacional baseado na junção entre capitalismo atrasado e democracia crescente, que o país vivia desde a década de 30. Para os autores em 1970 essa crise, ainda emergente, aparecia como parcial. A necessidade de superá-la, teria significado para as forças políticas apresentar projetos globais para a sociedade baseados na opção entre um dos dois aspectos do desenvolvimento chileno (desenvolvimento econômico ou democrático). O projeto da esquerda foi, neste sentido, condicionado à democracia, e, portanto, segundo esta perspectiva, tratava-se de um projeto de "democratização não capitalista". Contudo, a polarização político ideológica acabou minando a legitimidade institucional do sistema, que era primordial para esta proposição.

Podemos verificar, e esta é uma das críticas formuladas por Aggio (1993), que esta tese de Garreton e Moulian desdobra-se da tese do desajuste entre desenvolvimento econômico e desenvolvimento político ${ }^{21}$, pois é nesse sentido que para os autores a "via chilena" representou um programa que abrangia ao mesmo tempo ruptura -com a estrutura capitalista- e continuidade com a estrutura institucional democrática.

Um dos primeiros analistas a romper com a tese do desajuste, Tironi (1986), afirma que o que entrou em crise em 1970 foi o equilíbrio que o país tinha vivido desde 1930, entre desenvolvimento econômico, participação social e democracia política. A correlação equilibrada entre estes três processos foi denominada por este autor de "arreglo democrático". Tironi afirma ainda, que as sucessivas experiências democráticas que governaram o país durante 40 anos punham ênfase ora em um ora em outro desses aspectos, sustentando tais ênfases através dos consensos partidários. Contudo, no governo da Unidade Popular a esquerda tentou exacerbar simultaneamente todos os aspectos, ou seja, tentou potencializar a participação social, a democracia política e o desenvolvimento econômico, à diferença que este último caminhava agora no sentido da planificação econômica. Tal atitude, somada à polarização partidária, levou ao esgotamento total do "arreglo" que, finalmente, se traduziu em um grande conflito institucional entre Executivo, Legislativo e Judiciário.

Por outro lado, Aggio (1993) afirma que a esquerda interpretava o desajuste como sendo a expressão da contradição do desenvolvimento capitalista, desde aí que a crise de 1970 teria sido vista como uma crise total do próprio sistema e também como o momento culminante para o desenvolvimento do processo histórico revolucionário. ${ }^{22}$

\footnotetext{
${ }^{21}$ Esta tese foi apresentada anteriormente através da exposição das idéias de Pinto (1970).

22 Ao contrário do que afirmam Garreton e Moulian (1983).
} 
Sendo assim, para uma importante parcela deste agrupamento político, a superação da crise de desenvolvimento somente se realizaria com a superação da ordem democrática

vigente e não com sua continuidade. Para o olhar gramsciniano de Aggio, a Unidade Popular desencadeou um processo de "anti-revolução passiva", que rompeu com a "revolução passiva" a la chilena, iniciada no final da década de trinta, porque ao final, as políticas levadas a cabo pelo governo não consideraram o nexo existente entre consenso político e mudança estrutural vividos até então pela sociedade.

Podemos afirmar que, a crise do consenso político e sua institucionalização são temas bastante recorrentes quando se trata da ruptura com o sistema democrático no Chile. Tomando esses argumentos e retomando a perspectiva institucional, a qual se referiu anteriormente, Sartori e Valenzuela demonstram ser dois autores de suma importância para o estudo do caso chileno e das proposições teóricas que resultam de sua análise (SARTORI, 1982, 1993; VALENZUELA, 1989, 1991, 1998).

Para Valenzuela (1998), a presença de um sistema multipartidista não foi a única causa das dificuldades que enfrentaram os dirigentes políticos no período da Unidade Popular. Segundo o autor, ao estudar qualquer sistema político não é suficiente centrar-se unicamente no sistema de partidos, é essencial examinar a inter-relação entre as expressões políticas da base social, o sistema de partidos e o marco institucional de governo, mecanismos mediante os quais se resolvem os conflitos e se levam a cabo as políticas públicas. A tese central do autor nas obras às quais nos referimos aqui, é a de que a crise da democracia no Chile em 1973 se deveu à falta de congruência entre o polarizado e competitivo sistema de partidos e o sistema institucional. Ou seja, à impossibilidade de compatibilizar a existência de um marco constitucional presidencialista, com eleições de ganhador único, e um sistema multipartidista polarizado.

Esse autor ainda afirma que, recorrentemente as regras do jogo político próprias do presidencialismo geram pressões que socavam a lógica de formação de coalizões. Este olhar revela seu posicionamento profundamente crítico frente a esse regime de governo. Para o autor, na história política chilena o que teria permitido o país superar as dificuldades impostas pelo presidencialismo teria sido a existência de forças políticas de centro bastante pragmáticas, mas a erosão gradual dos cenários de compromisso político, em especial da assembléia legislativa, intensificaram a política de confrontação no país, tornando mais difícil negociar acordos políticos.

Dialogando com Sartori (1982) e Valenzuela (1989), afirmam que o desgaste de todas as possibilidades de negociação durante o governo de Allende se 
deveu ao papel de agente centrifugo que jogou o centro político. Os impulsos centrífugos teriam isolado a esquerda no Executivo e a oposição no Legislativo, às regras institucionais impediram a caída do governo e favoreceram a sua paralisação desencadeando o processo de ruptura com a democracia.

Finalmente, Valenzuela $(1989,1991,1998)$, conclui que o presidencialismo prende qualquer país a uma única opção por um período de tempo longo e invariável, ou seja, o mandato presidencial. Essa realidade geraria, em contextos multipartidários marcados pela polarização ideológica, como o chileno, uma intensa disputa pelo poder do presidente, disputa esta que, por sua vez, impediria os cenários de compromisso duradouros. Sendo assim, a solução para um impasse, praticamente certo, entre os poderes do Estado não reside na mudança do sistema eleitoral ou do sistema partidário, tal como a própria experiência chilena de reformas nesses sistemas teria demonstrado.

Tais reformas, conduzidas pelos militares chilenos, buscaram transformar o multipartidismo em bipartidismo à semelhança do sistema norte-americano. Mas segundo o autor em tela, essas transformações fracassaram em seu intento, uma vez que depois de quase uma década a "Concertación de partidos por la democracia”, coalizão partidária de centro esquerda formada para fazer frente à direita, se desestrutura e volta a configurar-se no Chile o antigo espectro político tripolar. Ao fim e ao cabo, esse autor chegou à conclusão de que não se muda a fisionomia de um sistema de partidos arraigado em uma sociedade, simplesmente com a mudança das leis e propõe a mudança de regime para parlamentarismo. Esse regime estimularia a formação de maiorias estáveis e redimiria crises, com a mudança de governo funcionando como um mecanismo de redenção da democracia ${ }^{23}$.

\section{O enfoque institucional sobre a experiência chilena e algumas de suas possibilidades.}

As análises de Valenzuela $(1989,1991,1998)$, pautam-se no estudo da dinâmica dos partidos em quanto instrumentos de coleta de votos e nos escrutínios eleitorais, seus trabalhos estão repletos de gráficos e tabelas dos resultados eleitorais e também dos tipos de conflitos e demandas sociais do período do governo de Allende.

\footnotetext{
${ }^{23}$ É imprescindível frisar aqui que, embora ainda não haja um estudo mais detalhado sobre o tema, a realidade atual da Concertação de partidos pela democracia no Chile demonstra claramente que a coalizão está longe de ruir. Todas as pesquisas realizadas sobre a eleição presidencial de dezembro de 2005 indicam que o candidato da coalizão de centro-esquerda ganharia já no primeiro turno. Sendo assim, é possível visualizar antes uma manifestação de unidade política do que uma manifestação de fragmentação.
} 
No que diz respeito às proposições sobre o presidencialismo e o parlamentarismo, este autor formula um panorama geral dos mecanismos que comporiam estes dois tipos de regime e sua influência em contextos políticos caracterizados pelo multipartidismo. A relação que estabelece entre regime de governo, sistema de partidos e ruptura institucional não trabalha, por exemplo, com as normas específicas do presidencialismo chileno, as quais delimitavam o jogo político interno aos poderes do Estado, e com a forma particular com que os distintos representantes lidaram com estas normas produzindo determinados resultados.

É possível afirmar, para citar um ponto, que a produção legislativa foi um núcleo gerador de conflitos entre governo e oposição durante o governo da UP. No entanto, não há disponibilidade de dados nas obras de Valenzuela, que indiquem em que medida as normas institucionais reguladoras das relações entre Executivo e Legislativo e concernentes à produção legal determinaram os resultados positivo ou negativos desta produção. $\mathrm{O}$ mesmo se pode dizer sobre a medida de atuação desses poderes em tal produção.

Não foi, por fim, estabelecida uma relação entre a organização do trabalho legislativo, produção legislativa e condução desse processo pelos distintos representantes, a despeito do autor afirmar que o desenho do regime político no Chile definiu o desfecho de 73.

É intrigante que Valenzuela releve critérios idiossincráticos, como o arraigo do sistema partidário na sociedade, para fundamentar a necessidade de mudança de regime no país em tela, e não releve este mesmo critério em relação à configuração institucional, uma vez que está claro que o presidencialismo foi uma opção histórica no Chile. Se não é possível mudar a fisionomia de um sistema de partidos com a simples mudança de leis, tal como afirma, nada indica que a mudança de modelo de regime político transforme as práticas institucionais em uma sociedade que desde sua gênese institucional e política vive sob a égide presidencialista e da competitividade partidária.

Por outro lado, o tema das relações entre sistema partidário e regime de governo pode ser mais elucidado pelo trabalho de Sartori $(1982,1993)$. Segundo o autor, para medir a eficácia de um regime político é necessário verificar o contexto especifico do sistema eleitoral, do sistema partidário e da cultura política de determinada realidade.

Sobre as relações destes critérios com o regime presidencialista na América Latina Sartori verificou que o "desempenho dos países governados por presidentes é bastante ruim", mas que o que funciona mal é o "presidencialismo puro" (SARTORI, 1993, p.5).

Neste sentido, este autor alerta para o fato de que recorrentemente no debate político, esta constatação leva à proposição do "parlamentarismo puro" 
Entretanto, ambas as formas "puras" podem apresentar "falhas intransponíveis" de acordo com o contexto em que se aplicam. De acordo com essa reflexão, a "flexibilidade" ou a "rigidez" dos regimes não são sinônimos de eficácia na manutenção do sistema político democrático (SARTORI, 1993, p.6).

Sartori defende para tanto a aplicação dos regimes "mistos", mas salienta que "em política a melhor forma é a que se aplica melhor" ressaltando, assim, a importância das práticas institucionais dos atores políticos para os trabalhos de análise dos distintos contextos políticos (SARTORI, 1993, p.8).

Em relação ao caso chileno, este cientista político italiano afirma que o ponto chave para entender como a crise do sistema democrático se configurou, está em apreender que a combinação entre eleições diretas para presidente e um alto padrão de ideologização partidária tem grandes possibilidades de enfraquecer a capacidade mediadora do centro -esta capacidade é essencial na manutenção do consenso político -, a não ser que o centro ocupe a presidência e dirija os acordos.

Desta maneira é possível afirmar que se demonstrou ser essencial relevar critérios como o grau de "polarização ideológica" dos partidos, como também a organização interna dos poderes do Estado e a relação entre esses poderes determinada pelas atividades dos distintos representantes em consonância ou não com as normas do jogo político institucional pré-estabelecidas.

Para tanto é primordial trabalhar com a definição de pluralismo polarizado. Conceito elaborado pelo autor a fim de criar uma tipologia para os sistemas de partidos em sistemas competitivos. Além disso, também é mister trabalhar com bases empíricas sistemáticas que permitam uma análise objetiva das atividades do legislativo em relação às atividades do governo. Estas bases podem ser proporcionadas por um vasto conjunto de material históricos do período, que inclui jornais, revistas, anais do Congresso, programas de governo entre outros, ainda pouco explorados pelos analistas.

\section{REFERÊNCIAS}

AGGIO, A. Democracia e Socialismo: a experiência chilena. São Paulo: UNESP, 1993. AGGIO, A. Revolución y democracia en el Chile de Salvador Allende. In: ALCÁZAR, Joan del y TABANERA, Nuria (Coord.). Estudios y materiales para América Latina 1955. 1990. Tirant lo blanch: Universitat de València, 1998.

AGGIO, Alberto. Revolução e democracia no nosso tempo. 2. ed. Franca: UNESP, 1997. (Série Estudos).

CÁCERES Q. G.; GARRIDO, J. A. El processo político chileno: de la consolidación a la crisis de la dominación oligárquica. In: TABANERA, Nuria; GARRIDO, Joan Alcázar; CÁCERES Quiero, Gozalo. Las primeras democratizaciones en America Latina: Argentina 
y Chile, 1880-1930. Trant lo Blanch: Universitat de Valencia, 1997.

DUJISIN, I. T. História de los cambios del sistema electoral en Chile, a partir de la Constitución de 1925. Santiago: FLACSO, 1989.

GARRETON, M. A.; MOULIAN, T. La Unidad Popular y el conflicto politico en Chile Santiago: CESOC, 1983.

JOCELYN-HOLT L, A. El peso de la noche: nuestra frágil fortaleza histórica. Argentina: Ariel, 1997.

LECHNER, N. A modernidade e a modernização são compatíveis? O desafio da democracia latino-americana. Lua Nova, São Paulo, n. 21, p. 73-89, 1990.

MOULIAN, T. La forja de las ilusiones: el sistema de partidos 1932-1973. Santiago: ARCIS, LOM, 1993.

MOULIAN, Tomas. Desarrollo político y estado de compromiso, desajustes y crisis estatal en Chile. Estudios CIEPLAN, Santiago, n.8, p.105-58, Jul. 1982.

MOULIAN,T. Tensiones y crisis política: análisis de la década de 1960. In: ALDUNATE, Adolfo; FLISFISH, Angel; MOULIAN, Tomas. Estudios sobre el sistema de partidos en Chile. Santiago: FLACSO, 1985.

PINTO, A. Desarrollo económico y relaciones sociales en Chile. In: PINTO, Aníbal. Tres ensaios sobre Chile y America Latina. Buenos Aires: Solar, 1970.

SARTORI, G. Partidos e sistemas de partidos. Brasília: UNB, 1982.

SARTORI, G. Nem Presidencialismo, nem Parlamentarismo. Revista Novos Estudos CEBRAP, São Paulo, n. 35, p. 3-14, mar. 1993.

TIRONI, E. El liberalismo real. Santiago: SUR, 1986.

VALENZUELA, A. A opção parlamentarista para América Latina. Lua Nova, São Paulo, n.24, p.55-71, set. 1991.

VALENZUELA, A. El quiebre de la democracia en Chile. Santiago do Chile: FLACSO, 1989.

VALENZUELA, A. La política de partidos y la crisis del presidencialismo en Chile: una propuesta para una forma parlamentaria de gobierno. In: LINZ, J.; VALENZUELA, A. (Comp.). La crisis del presidencialismo: el caso de Latinoamérica. Madrid: Alianza Universal, 1998. v.2, p.11-94.

VERDUGO M., M. Manual de derecho e instituciones políticas. Santiago do Chile: Jurídica, 1998. v.2. 
